damage, or alcoholic liver disease and may lead to coma and death.

The cause of encephalopathy is usually accepted as the passive transfer of toxins from the gut to the brain, though a possible second factor is impairment of hepatic synthesis of active neurotropic substances. Among the biochemical changes suggested as causes of the encephalopathy have been increased concentrations of ammonia and of aromatic amino-acids, a decrease in branched-chain amino-acids and increases in serotonin and short-chain fatty acids, the presence of false neurotransmitters such as octopamine and phenylethanolamine, and altered metabolism of prostaglandins and neuroendocrine peptides.

The established treatment for controlling encephalopathy includes emptying the bowel by purgatives or enemas and a diet low in protein. Manoeuvres to alter the colonic flora and decrease the uptake of toxins are also useful, and lactulose is the drug of choice. Neomycin is similarly effective, but its side effects prohibit more than brief use. Colonic exclusion by ileostomy is rarely required nowadays.

Newer treatments for hepatic encephalopathy include levodopa, bromocriptine, charcoal haemoperfusion, and liver transplantation. Levodopa may work by replenishing the true brain neurotransmitters, releasing other competing transmitters, or by stopping formation of methylamines. First used in massive dosage in fulminant hepatic failure 10 years ago, it had a striking arousal effect in the patient treated. ${ }^{1}$ Side effects limit the dose that can be given, but levodopa has been used with apparent benefit in both acute and chronic encephalopathy. ${ }^{2-4}$ As the disease itself is heterogeneous it is difficult to assess in these studies how many of the recoveries were spontaneous. An attempt to throw light on the issue was a report of the use of levodopa with or without a decarboxylase inhibitor in 75 patients with cirrhosis. ${ }^{5}$ No useful effect was shown. Nevertheless, as these patients were predominantly alcoholics who had developed encephalopathy because of gastrointestinal bleeding or alcoholic intoxication, this superbly conducted prospective double-blind randomised placebo-controlled trial could be criticised on the grounds that the patients were quite the wrong sort. Furthermore, the effects of levodopa do not persist and are not seen at all in severe chronic encephalopathies, so this treatment remains of unproved value.

Bromocriptine is a dopamine agonist which was found to be effective in combination with lactulose in six patients with intractable stable severe encephalopathy. ${ }^{6}$ It offered no advantage in another study of seven less severely affected patients, in whom it was used as an alternative to standard treatment. ${ }^{\text {? }}$ Like levodopa, bromocriptine may have some place in the management of hepatic encephalopathy, but use of these drugs is strictly a research project at present.

Charcoal haemoperfusion and liver transplantation are responses to the desperate condition of many patients with severe liver disease. They certainly have an impact on encephalopathy in the short term, but the effect on survival is still being evaluated. In most patients standard treatment with diet, purgation, lactulose, and avoidance of unnecessary psychotropic drugs are the routine-and probably the bestremedies for chronic hepatic encephalopathy. Other measures may become useful adjuncts, but there have been too many false dawns already.

\footnotetext{
${ }^{1}$ Parkes JD, Sharpstone P, Williams R. Levodopa in hepatic coma. Lancet 1970;ii:1341-3.

2 Abramsky O, Goldschmidt Z. Treatment and prevention of acute hepatic encephalopathy by intravenous levodopa. Surgery 1974 ;75:188-93.
}

${ }^{3}$ Lunzer M, James IM, Weinman J, Sherlock S. Treatment of chronic hepatic encephalopathy with levodopa. Gut 1974;15:555-61.

4 Fischer JE, Funovics JM, Falcao HA, Wesdorp RIC. L-dopa in hepatic coma. Ann Surg 1976;183:386-91.

${ }^{5}$ Michel H, Solere M, Granier P, et al. Treatment of cirrhotic hepatic encephalopathy with L-dopa. A controlled trial. Gastroenterology 1980; 79:207-11.

${ }^{6}$ Morgan MY, Jakobovits AW, James IM, Sherlock S. Successful use of bromocriptine in the treatment of chronic hepatic encephalopathy. Gastroenterology 1980;78:663-70.

7 Uribe M, Farca A, Márquez MA, Garcia-Ramos G, Guevara L. Treatment of chronic portal systemic encephalopathy with bromocriptine. A double-blind controlled trial. Gastroenterology 1979;76:1347-51.

\section{Metabolic obesity?}

Few people nowadays would sympathise with the position of the affluent Victorian mill owner haranguing his impoverished workforce on the virtue of thrift: in these enlightened times we realise that the low wages he paid were an important cause of poverty. Similarly, our views on the cause of obesity have become more liberal: many fat people eat no more than many thin people, so that obesity cannot be ascribed entirely to the vices of sloth and gluttony. Nevertheless, the laws of thermodynamics apply to man as much as to steam engines, and no organism can store energy as fat unless its intake of energy exceeds its output. The search is on, therefore, for ways in which obese people run at a lower energy cost than the rest of the population.

In general, when the energy expenditure of obese individuals is compared with that of lean, the obese ones have the higher metabolic rate. ${ }^{1}$ In theory, a subgroup of obese people, perhaps characterised by a family history of obesity or obesity of early onset, might be found to have an unusually low metabolic rate; no such group has been identified. ${ }^{2}$ There is some evidence that obese people are less physically active than lean ones, but a given level of activity requires more energy from a heavy person than a light one so that physical inactivity cannot provide a realistic basis for substantial savings on energy expenditure. ${ }^{3}$

Recent work on the obese (ob/ob) mouse has shown that an important factor in its genetically determined obesity is a decreased thermogenic response to cold. ${ }^{4}$ In circumstances in which the lean animal would increase heat production the $\mathrm{ob} / \mathrm{ob}$ mouse does not. The result is that if it does not die of hypothermia it has more energy to lay down as fat. The biochemical defect which leads to this impaired thermogenic response has been traced to brown fat. ${ }^{5}$ Is there an analogous metabolic defect in at least some obese humans?

Probably there is. A research group in Lausanne has shown that the increase in metabolic rate after an oral load of $50 \mathrm{~g}$ glucose was smaller in obese than in lean persons. ${ }^{6}$ After an infusion of noradrenaline (which mimics the action of coldinduced thermogenesis) obese people showed a smaller response than lean people, as did people of normal weight who had formerly been obese. ${ }^{7}$ There is still controversy about the relevance of brown fat to these reactions in adult man: the mouse is a small animal which needs an efficient heat-generating apparatus to survive, but keeping his body temperature constant is less of a struggle for a large animal such as man.

The latest suggestion for an energy-saving metabolism which may be relevant to obesity comes from Boston. ${ }^{8}$ A study there showed that the red cells of obese people had fewer sodium-potassium pump units than red cells from lean 
people, an observation confirmed by the higher sodium concentration inside the cells of obese people. These abnormalities persisted even after a loss of weight. A similar defect in sodium pumping has been shown in genetically obese mice. ${ }^{9}$ Pumping sodium out of cells requires energy, and measurements in the laboratory show that most of the thermogenic response to thyroid hormone may be explained by increased transport of sodium. ${ }^{10}$

There are, therefore, several pieces of evidence that obese people show a smaller increase in metabolic rate to many stimuli such as food, cold, and thyroid hormone. Do we therefore owe an apology to all the obese patients whom we have accused of overeating ? To some of them, perhaps, but not to all. If fat and thin people who are each maintaining weight are put in a direct calorimeter for 24 hours the former produce more heat than the lean ones, ${ }^{11}$ so it cannot be argued that the obese have a lower food intake.

1 James WPT, Davies HL, Bailes J, Dauncey MJ. Elevated metabolic rates in obesity. Lancet $1978 ; \mathrm{i}: 1122-5$.

2 Garrow JS, Blaza SE, Warwick PM, Ashwell MA. Predisposition to obesity. Lancet $1980 ; \mathrm{i}: 1103-4$.

${ }^{3}$ Garrow JS. Energy balance and obesity in man. 2nd ed. Amsterdam: Elsevier/North Holland, 1978.

4 Thurlby PL, Trayburn P. The role of thermoregulatory thermogenesis in the development of obesity in genetically-obese (ob/ob) mice pair-fed with lean siblings. $\mathrm{Br} \mathcal{F}$ Nutr 1979;42:377-85.

${ }^{5}$ Himma-Hagen J. Cellular thermogenesis. Annu Rev Physiol 1976;38: 315-51.

${ }^{6}$ Pittet $\mathrm{Ph}$, Chappuis $\mathrm{Ph}$, Acheson $\mathrm{K}$, De Techtermann F, Jéquier E. Thermic effect of glucose in obese subjects studied by direct and indirect calorimetry. Br $\mathcal{F}$ Nutr $1976 ; 35: 281-92$.

${ }^{7}$ Jung RT, Shetty PS, James WPT, Barrand MA, Callingham BA. Reduced thermogenesis in obesity. Nature 1979;279:322-3.

${ }^{8}$ De Luise M, Blackburn GL, Flier JS. Reduced activity of the red-cell sodium-potassium pump in human obesity. $N$ Engl f Med 1980;303: 1017-22.

${ }^{9}$ Lin $\mathrm{MH}$, Romsos DR, Akera T, Leveille GA. $\mathrm{Na}^{+}, \mathrm{K}^{+}-\mathrm{ATPase}$ enzyme units in skeletal muscle from lean and obese mice. Biochem Biophys Res Commun 1978;80:398-404.

${ }^{10}$ Smith TJ, Edelman IS. The role of sodium transport in thyroid thermogenesis. Fed Proc 1979;38:2150-3.

11 Blaza SE, Garrow JS. The thermogenic response to comfortable temperature extremes in lean and obese subjects. Proc Nutr Soc 1980;39:85A.

\section{Chronic intestinal ischaemia}

Arterial insufficiency of the intestine rarely causes abdominal symptoms, but the diagnosis should be kept in mind in patients in whom conventional investigations have shown no more usual cause for postprandial pain, perhaps radiating through to the back, reluctance to eat, and loss of weight. Diseases such as peptic ulcer, tumours of the digestive tract, and biliary or pancreatic disorders have to be confidently excluded, but once this has been done chronic intestinal ischaemia becomes a real possibility.

The most likely underlying arterial disorder is atherosclerosis. Routine postmortem surveys show that partial or complete occlusion of the coeliac and mesenteric arteries by atheromatous plaques is quite common. The fact that clinical manifestations occur so seldom is a tribute to the rich collateral arterial supply of both the small and the large intestine.

In its acute form intestinal ischaemia of the small bowel is due to sudden occlusion of (usually) the superior mesenteric artery by embolus or thrombus at the site of an atheromatous plaque. Often a lengthy segment of gut will be infarcted and may require resection; or the surgeon may attempt to restore the arterial flow either by embolectomy or by an arterial graft.

Occlusion of the inferior mesenteric artery or one of its main branches usually causes much less dramatic features, causing lower abdominal pain of sudden onset, tenesmus, and the passage of blood or bloody diarrhoea. The vascular damage to the wall of the colon is usually much less extensive, and recovery is usual, with or without stricture formation.

The clinical presentation of chronic intestinal ischaemia is different, but we do not know whether the presence of the chronic pattern, indicating some impairment of arterial flow, predisposes to acute complete occlusion. The clinical evidence suggests that this is not necessarily so.

The clinical manifestations of chronic ischaemia of the small and large bowel are different. In the small intestine ischaemia causes "intestinal angina" or "mesenteric intermittent claudication"-cramping mid- or upper-abdominal pain, starting 10-15 minutes after a meal, increasing in severity, reaching a plateau, and thereafter gradually subsiding in about one to two hours. The pain may be cramping or a diffuse ache and at its height may be described as intense; it may radiate through to the back. Additional complaints include bloating and flatulence; diarrhoea or steatorrhoea may develop; and occasionally vomiting may be a feature. The size of meal may affect the overall severity of the symptoms, and as a result patients may eat progressively less and lose weight. A few patients find that leaning forwards may relieve their symptoms. Clinical examination generally shows no specific signs apart from evidence of weight loss. A systolic bruit may be heard over the upper abdomen, but too much reliance should not be placed on this sign, since such a bruit is found in as many as one in every eight healthy adults.

Once the diagnosis is considered, confirmation should be sought by aortography, with attempts made selectively to cannulate the coeliac and superior mesenteric arteries and possibly also the inferior mesenteric artery. Both anteroposterior and lateral views should be taken: the former will give information on the degree of collateral supply, and the latter will outline the arteries themselves, showing any narrowing or blockage. Usually more than one of the three main vessels has to be occluded to produce symptoms-and here again caution is needed, for considerable obstruction to one or more of these vessels is a not uncommon finding on aortography performed for other reasons in patients without any abdominal complaint.

When, however, good evidence is found of obstruction of the coeliac or superior mesenteric artery or both in a patient with characteristic clinical features, what can be done to help? Several surgical approaches have been used since the late 1950s. Initially endarterectomy of the proximal portions of the main vessels was tried but was found both to be technically difficult and to give unsatisfactory results. Even the addition of patches of vein or synthetic materials failed to improve the outcome. More recently much better results have been reported from one or other form of graft procedure using saphenous vein or Dacron tube between the anterior wall of the aorta and the patent segment of the superior mesenteric artery. Other possible methods of reconstruction include reimplantation of the artery directly into the aorta and aortosplenic artery bypass of the coeliac vessel. If both arteries are occluded symptoms are relieved if flow is restored to only one.

In general the immediate and medium-term results of these bypass procedures are good, with over $70 \%$ of patients relieved of troublesome symptoms. Rare though the clinical problem may be, since operative treatment is reasonably successful the possibility should be borne in mind-there should be no doubt that the vascular occlusion is truly the cause of the symptoms. 